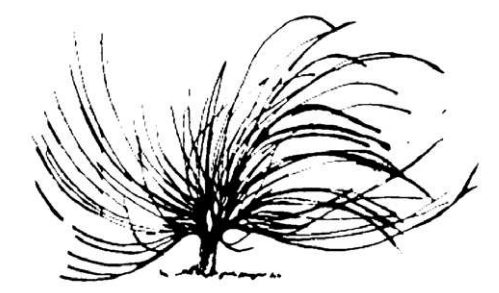

\title{
Exclusión social como práctica pedagógica en la economía mundo capitalista: el caso del abandono del sistema educativo formal costarricense por jóvenes entre los 12 y los 18 años de edad (2000-2010)
}

\author{
Ernesto Herra Castro ${ }^{1}$ \\ Universidad Nacional de Costa Rica \\ Heredia, Costa Rica \\ ernestoherra@hotmail.com
}

\begin{abstract}
Resumen
El texto analiza las relaciones económicas, históricas, políticas, sociales y pedagógicas que ha tenido la institución educativa con el desarrollo histórico de la economía-mundo capitalista, estableciendo una lectura dialéctica que permite comprender la exclusión del sistema educativo formal costarricense en jóvenes entre los 12 y los 18 años de edad entre los años 2000 y 2010.
\end{abstract}

Palabras clave: Centroamérica, Costa Rica, capitalismo, imperialismo, exclusión educativa, exclusión social, jóvenes

\begin{abstract}
This text analyzes the economical, historical, political, social and pedagogical relations that the educational institution has had with the historical development of the capitalist world-economy, establishing a dialectical reading that understands the exclusion of formal education in
\end{abstract}

Recibido: 3 de marzo de 2013 - Aprobado: 11 de octubre de 2013

1 Maestría en Estudios Latinoamericanos. Trabaja actualmente como académico en sociología e investigador en un proyecto de la División de Educología de Alfabetización crítica. 
Costa Rican youth from 12 to 18 years old between the years 2000 and 2010 .

Keywords: Central America, Costa Rica, capitalism, imperialism, educational exclusion, social exclusion, youth

\section{Introducción}

$\mathrm{E}$ 1 presente trabajo surge como resultado de las reflexiones y discusiones propias del equipo de investigación del proyecto denominado "Alfabetización crítica en la cultura escolar: Sociedad y Derechos Humanos" que comparten la Escuela de Sociología y la División de Educología de la Universidad Nacional de Costa Rica, el cual ha establecido un acercamiento crítico al fenómeno educativo con miras a establecer nuevos acercamientos y aportes al abordaje del fenómeno educativo en el contexto nacional costarricense. De esta forma, se intenta con este documento, visibilizar y explicar el fenómeno de la exclusión del sistema educativo formal costarricense por parte de decenas de miles de jóvenes entre los 12 y los 18 años de edad, los cuales, por encontrarse fuera del sistema educativo como un todo, no son siquiera contemplados en las cifras oficiales del Ministerio de Educación Pública costarricense y han sido obviados del proceso de problematización y análisis del fenómeno educativo en este país.

Dado que lo que se trata aquí, es intentar explicar a qué se debe que este grupo importante de jóvenes se encuentre en condiciones de abandono del sistema educativo formal costarricense, se utilizarán dos modelos explicativos, el conceptual y el nomológico deductivo, que intenten dar cuenta de nuestro objeto de estudio. De esta forma, se establece un análisis científico desde la mirada sociológica, lo cual indica que se establecerá en adelante un acento particular en la acción social como imagen que mediará el proceso investigativo.

El trabajo aquí expuesto se plantea como un proceso dialéctico en el cual las contradicciones propias del desarrollo histórico capitalista condicionan, se imponen y modelan el fenómeno educativo, al mismo tiempo en que es la institucionalidad educativa quien valida, fomenta, reproduce y legitima los sentidos propios del desarrollo histórico capitalista, así la exclusión educativa se enmarca en una matriz de análisis amplia mediante la cual sus relaciones, prácticas y significados cobran nuevos sentidos. 


\section{Elementos teórico-metodológicos}

Según Hessen (1993) el proceso de construcción de conocimiento establece de partida una relación dual entre el sujeto y el objeto. Dado que la relación que se establece entre quien conoce, el Sujeto, y lo que se desea conocer, el Objeto, no está determinado por el Sujeto sino por la "Imagen" que éste posee del Objeto, la imagen que media esta relación está a cargo de la sociología, la cual se constituirá, en el marco del presente análisis, como "el medio por el cual la conciencia cognoscente aprehende a su objeto" (Hessen, 1993, p. 25).

Dado que el fenómeno educativo costarricense se expresa en unas prácticas, en unas relaciones, en unos significados que han sido moldeados en una racionalidad específica y que es precisamente en el marco de esta racionalidad que el fenómeno educativo se ha articulado en el contradictorio desarrollo histórico capitalista, es que se entiende la exclusión del sistema educativo formal como aquella decisión, que aún siendo individual, está mediada por aspectos objetivos que se expresan en el ámbito de la desigualdad, de tal forma que las expresiones antagónicas de la economía-mundo capitalista se validan, reproducen y legitiman en el ámbito educativo como una dinámica de mutuos modelamientos en el que lo económico se impone sobre lo educativo al tiempo que lo educativo legitima el caos imperante.

En el marco de este documento, se entenderá por exclusión del sistema educativo, el proceso objetivo mediante el cual un sector de la población en edades propias de atender el sistema educativo formal, constituidos por personas entre los 12 y los 18 años de edad, no están incorporados, ni en apariencia, a la dinámica educativa formal, razón por la cual no son contempladas ni contemplados en las cifras educativas. En este caso particular se identifican a las y los jóvenes que han abandonado el sistema educativo formal, razón por la cual la tabla estadística construida enfatiza a aquellas y aquellos que han abandonado, y no, necesariamente, a aquellos y aquellas que, habiendo matriculado al inicio del proceso educativo, fueron expulsados del proceso. Estas y estos últimos deberían ser contemplados, incluso, dentro de la población excluida, lo que elevaría significativamente la cifra. No se ha procedido de esta forma dado que quienes "desertan" constituyen un universo cualitativamente distinto que quienes ni siquiera logran matricular. Será motivo de futuras reflexiones analíticas establecer una comparación entre ambos universos. 
En este sentido la exclusión educativa guarda relación con la concepción propia de la exclusión social, la cual se entiende como la privación relativa de los bienes y la inversión pública, así como la exclusión de los derechos sociales, políticos y económicos (Fiszbein, 2001, p. 235), que están estrictamente relacionados con la matriz general que sostiene la propia dinámica de explotación capitalista.

En tanto a posibilidad de conocimiento, se establece un ejercicio en el cual se establece una intermediación entre la razón y la experiencia, en la cual será la razón la que conduzca el ejercicio explicativo. De esta forma, las experiencias educativas que aquí se muestran en tanto a dato, se entienden como la materia del conocimiento que será expresada y ordenada a través de la razón. Este particular permite ubicar a la información estadística que ha sido necesaria de construir para el presente análisis, como una herramienta que da cuenta de la vivencia del fenómeno educativo por medio del cual se intentan develar las características de la expulsión de jóvenes del sistema educativo formal costarricense en la cual la razón imprime el hilo conductor y determinante en el presente análisis. De esta forma, la información estadística aquí contenida no pretende en ningún momento elevarse a nivel de ley, sino permitir un ejercicio donde lo empírico permite comprender racionalmente el fenómeno en tanto acción social, por lo cual ha sido indispensable acentuar el sentido económico, histórico, político, social y pedagógico que median en el abandono del sistema educativo formal costarricense.

El sentido argumentativo y explicativo que sustenta el presente trabajo está fundamentado en la explicación conceptual y el modelo nomológico deductivo. La explicación conceptual, en tanto modelo explicativo, permite comprender la expulsión de jóvenes del sistema educativo formal costarricense en una matriz explicativa más amplia que permite leer al fenómeno educativo en su dinamicidad histórica. Según Hidalgo y Klimovsky (1998) al posicionarnos desde este modelo explicativo se parte de la identificación de dos hipótesis. La primera de ellas es la hipótesis de existencia de la estructura amplia, la cual "afirma que existe o tiene lugar un fenómeno amplio que nos proporcionará el contexto explicativo". La segunda hipótesis, denominada hipótesis de inserción, "afirma que lo que se quiere explicar se inserta y forma parte de la estructura amplia que hemos postulado" (Hidalgo y Klimovsky, 1998, p. 66), por lo cual en adelante se irán develando las relaciones 
dialécticas que se articulan entre la economía-mundo capitalista y el abandono del sistema educativo formal costarricense.

El segundo modelo explicativo utilizado para dar sustento a este trabajo es el nomológico deductivo, en el cual "la explicación es un razonamiento deductivo entre cuyas premisas aparecen, de manera esencial, enunciados con forma de ley (Hidalgo y Klimovsky, 1998, p. 29).

Atendiendo lo anterior, el referente, en tanto "premisas ley", de las que parte el presente trabajo, corresponde a las leyes de la dialéctica: la transformación de la cantidad en cualidad; la unidad de los opuestos; y la negación de la negación, las cuales permitirán evidenciar las relaciones antagónicas que se expresan en el ámbito educativo como expresiones de una dinámica de mutuos modelamientos que se establecen entre lo económico y lo educativo. De esta forma, la transformación de la cantidad en cualidad permite identificar las manifestaciones propias del desarrollo histórico capitalista, las cuales se establecen y modelan en el fenómeno educativo, de formal tal que el comportamiento de la exclusión educativa, en tanto a dato, debe ser entendida de manera articulada con la fase de desarrollo capitalista en el que el fenómeno intenta ser comprendido. Si se observa este elemento en detalle, la transformación de la cualidad en cantidad permite identificar las diversas expresiones que tiene el fenómeno educativo a través del tiempo, las cuales son modeladas por el momento histórico que atraviesa la base económica que le da sustento. De esta forma el abandono del sistema educativo formal por parte de jóvenes costarricenses, se expresa como condición básica para la reproducción capitalista.

La unidad de los opuestos permite identificar el grado de desarrollo e intensidad que el capitalismo imprime sobre el fenómeno en cuestión. Se trata de comprender la unidad e integralidad entre los elementos que han permitido el desarrollo histórico del capitalismo, para el cual la educación formal ha sido un pilar, como se establecerá en detalle en adelante.

De esta forma, se busca establecer un análisis que permita identificar la concepción dialéctica del desarrollo capitalista como un proceso de desaparición, de destrucción de lo viejo y de seguimiento de lo nuevo y no, estrictamente, como un análisis de tipo cuantitativo que responda al aumento o disminución del objeto del presente estudio.

La unidad de los opuestos permite identificar las contradicciones propias de la realidad objetiva que se manifiesta en el desarrollo 
antagónico del capitalismo y cómo éste se expresa en el abandono del sistema educativo formal costarricense. Lo anterior permite comprender las fuerzas y luchas que se exteriorizan en el desarrollo capitalista y cómo éstas se hacen eco en el fenómeno educativo, de tal forma que las contradicciones coexisten y se excluyen mutuamente.

Por último, se parte de la negación de la negación como ley. Esta muestra la tendencia del desarrollo material del capitalismo como modo de producción que da vida a sus nuevas fases, basadas en la negación de sus formas anteriores de existencia. Lo anterior permite identificar las dinámicas de vinculación que se tejen entre el desarrollo histórico capitalista en su fase superior monopolista y las nuevas expresiones que se dinamizan en el ámbito educativo en forma de abandono. De esta forma la implementación del modelo nomológico deductivo, basado en las leyes de la dialéctica, permite comprender, en tanto acción social, las diversas expresiones contradictorias que se dinamizan en la práctica educativa.

Se culmina señalando que las tablas estadísticas que se han diseñado para dar sustento al presente análisis han sido construidas a partir de la información recopilada en las Encuestas para Intereses y Propósitos Múltiples del Instituto Nacional de Estadística y Censos aplicadas entre los años 2000 y 2010. Esta información ha sido posible de construir gracias a la plataforma virtual del Centro Centroamericano de Población de la Universidad de Costa Rica, el cual permitió establecer los cruces de variables respectivos para este trabajo.

\section{Expansión imperialista, surgimiento de los estados-nación centro- americanos y dinámicas del poder asociados a la institución educa- tiva en Costa Rica}

Si bien es cierto, el fenómeno educativo cobra expresiones diversas y significativas en el ámbito del proceso de configuración y desarrollo histórico de los Estado-nación, este debe ser comprendido en una matriz más amplia, que permita comprender la articulación de la dinámica educativa en el proceso histórico de la división internacional del trabajo.

El desarrollo histórico de la economía-mundo capitalista tiene sus cimientos en los siglos XIV y XV, con una expresión más consistente a partir del siglo XVI. Sin embargo, no es hasta mediados del siglo XIX que se da el desplazamiento de la libre competencia, principal característica del capitalismo, por el imperialismo, cuya principal 
característica es el monopolio, la cual en esta nueva fase del desarrollo capitalista culmina consolidándose como un sistema de sojuzgamiento colonial y de estrangulación financiera para la gran mayoría de los países del planeta, cuya principal estrategia ha sido el desplazamiento de la pequeña producción por la producción a gran escala y a ésta por una aún mayor (Lenin, 1966, p. 695). De esta forma se articula, a escala planetaria, un sistema de organización económica y social fundamentado en la extracción de plusvalía, la cual se constituye en "el fin determinante, el interés impulsor y el resultado final del proceso de producción capitalista" (Marx, 2009).

El surgimiento de los Estados-nación en el continente americano se da "dentro del más vasto movimiento de descolonización general de todas las Américas, movimiento que provocado y desencadenado también por las dinámicas mundiales de la reorganización de la geopolítico europea y planetaria de finales del siglo XVIII y comienzos del siglo XIX, se combinan e imbrican con los procesos protonacionales y locales de cada una de las zonas de este vasto continente americano" (Aguirre, 2007). De esta forma, el proceso de resquebrajamiento del orden colonial preexistente, que había sido articulado en función de la explotación feudal, culminó por reorganizarse en la nueva lógica de explotación capitalista. Atendiendo lo anterior, se puede identificar a la ruptura de la Capitanía General del Reyno de Guatemala (1821-1823) y al surgimiento de los Estado-nación centroamericanos como un proceso articulado con la tendencia anexionista que el imperialismo desarrolló principalmente sobre las regiones agrarias de todo el planeta (Lenin, 1966, p. 764). Este elemento particular le permitió a la dinámica expansionista del imperialismo hacerse del control de nuevos y más voluminosos contingentes de materia prima y fuerza de trabajo para el proceso de reproducción capitalista. Así el modo de producción capitalista culmina por convertirse en "un sistema socialmente estructurado por una división axial integrada, cuyo principio rector es la acumulación de capital (división mundial del trabajo, relación entre capital mundial y fuerza de trabajo mundial, y relación centro-periferia entre, de un lado, los sectores más monopolizados de producción y, del otro, los más competitivos, elementos éstos que posibilitan y conforman la transferencia del plusvalor del sector, las formaciones sociales o las regiones periféricas, a los sectores, formaciones sociales o regiones centrales y de los asalariados a los no asalariados)" (Gandarilla, 2011, p. 64). 
Durante las primeras décadas de expansión del capitalismo en la región centroamericana, éste ya había alcanzado madurez en su fase monopólica, lo cual permitió articular una red de relaciones económicas transnacionalizadas en las cuales los grupos dominantes de naciente burguesía regional centroamericana fueron también accediendo al control de una porción minoritaria del capital monopólico y, en el caso particular de Centroamérica, se fue consolidando un circuito interno de acumulación sobre la base del fortalecimiento de la producción industrial urbana y de la extracción de mayores proporciones de plusvalía generada a nivel local (Quijano, 1982, p. 43).

La integración, cada vez más profunda, de los intereses de los grupos burgueses dependientes con los de la burguesía imperialista internacional se fue desarrollando en la medida que la ampliación de los circuitos de acumulación se fueron estableciendo (Quijano, 1982, p. 42). De esta forma, la organización que se articuló en Centroamérica en torno a la satisfacción de las necesidades provenientes de las economías imperialistas de la época (Inglaterra y Francia durante el siglo XIX y posterior a 1908 por los Estados Unidos), le permitió a una clase económica y social específica hacerse con el control del aparato estatal y sus instituciones, lo cual se constituyó en la principal victoria de los intereses extranjeros en la región centroamericana.

Las disputas oligárquicas, que mayoritariamente se reconocían liberales en el tanto respaldaban la noción impuesta por casi tres siglos "de que todo lo que le beneficiara al imperio era bueno, y malo todo lo que le fuera contrario" (Quesada, 2008, p. 24), se fueron desarrollando a través de la interacción de dos elementos cualitativamente distintos pero que de manera traslapada se extendieron durante el siglo XIX y que de alguna manera se mantienen hasta nuestros días: la crisis del Estado oligarca y el surgimiento de la economía capitalista. Esta última fue dejando en evidencia que las viejas relaciones de explotación, propias del colonialismo español, sólo habían sido desplazadas por nuevas formas de explotación. Es así, como la expansión del capitalismo por la región centroamericana se puede comprender "como desarrollo y continuación directa de las propiedades fundamentales del capitalismo en general" (Lenin, 1966, p. 761). Sin embargo, los elementos propios de la crisis del Estado oligarca tuvieron expresiones muy diversas, conflictivas y contradictorias a lo interno de la propia región centroamericana, en las cuales, para el caso costarricense, se identifican "claros mecanismos 
de explotación económica y subordinación social sobre el conjunto de los sectores populares, que en lo tocante a relaciones socioproductivas abarcaban un continuum desde el productor formalmente independiente, pero sujeto a anticipos y entregas cuasi-obligatorias, hasta el trabajador asalariado, quien no siempre lo era a tiempo completo" (Samper, 1988, p. 162).

Lo anterior fue posible a través de una combinación sui géneris entre el poder político-económico y la dinámica educativa, la cual atendió los factores estructurales que le habían sido impuestos a la región centroamericana como un todo: el mercado externo, la fuerza de trabajo y el monopolio de la tierra (Torres Rivas, 1974, p. 31). De esta forma, los sectores que controlaron y dominaron desde sus inicios los aparatos institucionales en Costa Rica se las ingeniaron para buscar mecanismos coercitivos "más sutiles o menos violentos para asegurar el ejercicio efectivo del poder" (Samper, 1988, p. 162), ante lo cual "adquirieron especial relevancia la educación, la formación de opinión pública, la participación política controlada, y la legitimación del propio Estado" (Samper, 1988, p. 162), los cuales guardan relación con las formas en las que se ejerce el poder económico y político aún en la actualidad.

El sistema educativo costarricense, "diseñado por los liberales decimonónicos e impulsado por sus sucesores durante las primeras décadas de este siglo" (Samper, 1988, p. 161-162), refiriéndose al siglo $\mathrm{XX}$, se encargó de difundir "entre la población urbana, crecientemente alfabetizada, las ideas de los miembros más ilustrados de dicha élite" (Samper, 1988, pp. 161-162), lo que permitió controlar y difundir las nociones ideológicas de la naciente burguesía nacional a través del sistema educativo. Según Samper (1988, pp. 161-162) "desde mediados del siglo XIX, hasta bien entrado el XX, el Estado costarricense fue controlado, en lo esencial, por una "clase" (social y política) bien específica desde el punto de vista de su composición, su papel en la actividad productiva del país y su interacción con otros sectores de la sociedad. Esta élite tenía como sustento económico la producción, el procesamiento y la exportación del café, así como el gran comercio importador y la intermediación financiera entre el capital inglés, principalmente, y los pequeños o medianos caficultores. En lo político, representantes directos o indirectos de esa clase accionaban los mecanismos primordiales del Estado, tanto en la conducción del poder ejecutivo, legislativo y judicial, como en la dirección específica de los medios 
institucionales para asegurar el control social, entre los cuales jugó un papel preponderante en Costa Rica el sistema educativo (...)".

De esta forma, la comprensión de la dinámica educativa costarricense debe ser entendida como un proceso de mutuos modelamientos, en el cual lo educativo se modela en consonancia con el desarrollo histórico capitalista, de tal forma que tanto uno como el otro son expresiones de un mismo fenómeno. Así, la economía mundo capitalista se establece como la matriz general, estructura amplia, sobre la que se dinamiza la dinámica educativa, entre cuyas expresiones se encuentra el abandono del sistema educativo formal.

\section{La exclusión del sistema educativo formal costarricense como hecho coherente de las asimetrías propias de la economía-mundo capitalista}

Independientemente del nombre con que se les llamó a los distintos experimentos que hicieron los países latinoamericanos a lo largo del siglo XX, por establecer sus propios modelos económicos articulados con la dinámica de la economía-mundo capitalista, fue el imperialismo la base sobre la que se articularon las relaciones geopolíticas a escala planetaria.

El año de 1908, marcó el desplazamiento del imperialismo inglés por el imperialismo estadounidense en la región centroamericana (Menjívar, 1980), lo cual significó una transformación cualitativa en las relaciones geopolíticas a escala planetaria, principalmente porque los Estados Unidos daba inicio a la exportación de capitales en esta región geográfica, lo que fue reforzado una vez transcurridas la Primera y la Segunda Guerra Mundial (Aguirre, 2007). Lo anterior, le permitió a este país consolidar una estructura amplia de redes corporativas de carácter transnacional que de alguna manera selló las relaciones "tripartitas" entre las "zonas centrales", las "semiperiféricas" y las "periféricas".

Según Aguirre (2007), "las zonas centrales serán casi siempre las generadoras de las nuevas tecnologías de punta y las sedes de los grandes monopolios transnacionales, desarrollando los niveles de ingreso, consumo y de vida más altos, y pagando los salarios más elevados en términos relativos, todo lo cual no son más que diversas expresiones y consecuencias de esa mayor riqueza que ellas concentran, al explotar por diversas vías a la semiperiferia, sobre todo a la vasta periferia que las circunda". Sin embargo, las transformaciones culturales que se suscitaron a escala planetaria en 1968, así como la crisis económica 
planetaria que estalló entre los años 1972-1973, minó las condiciones hegemónicas que habían sostenido, casi de forma ininterrumpida, los Estados Unidos a escala planetaria, lo que "comenzó el proceso, lento pero indetenible, de la decadencia total de la hegemonía norteamericana, la que se prolonga claramente hasta nuestros días" (Aguirre, 2007, p. 25), de tal forma que a este país no le quedó más que aliarse a su antigua potencia protectora: Inglaterra.

Al finalizar la década de los años setenta, el modelo de sustitución de importaciones, aplicado en América Latina como uno de sus experimentos entre los años 1950-1980, demostró la imposibilidad de desarrollar un capitalismo independiente, armónico, equilibrado y sin crisis, lo cual estaba en completa contradicción con el desarrollo histórico del propio capitalismo, concebido inicialmente por la CEPAL. Por el contrario, demostró que la dependencia económica que tenían los países latinoamericanos del capitalismo metropolitano les había llevado a una situación de crisis estructural que no podía ser solucionada a partir de las dinámicas "naturales" de intercambio comercial.

Aunado a lo anterior, el endeudamiento contraído entre las décadas de los años 60 y 70 del siglo XX por los gobiernos militares y las burguesías locales se amplió significativamente debido al incremento de las tasas de interés pactadas con los principales organismos financieros internacionales (Silva, 2006, p. 6). Asimismo, la región latinoamericana experimentó un aumento sin precedente en los precios internacionales del petróleo y vio como los precios de sus principales productos de exportación cayeron de manera estrepitosa al mismo tiempo que perdieron la capacidad de hacer frente a los pagos de los préstamos contraídos. De esta forma, la imposibilidad de los países latinoamericanos de asumir el costo de la deuda, que se puso de manifiesto a partir del caso de México en 1982, ofreció una excelente oportunidad para promover e implementar un programa neoliberal en la región, dados los resultados que ya habían obtenido producto del experimento aplicado en Chile desde 1973, el cual fue asumido con especial interés por las administraciones Tatcher (1979-1990) y Reagan (1981-1989). La concreción del programa neoliberal se concretó a través de la aplicación de los Programas de Ajuste Estructural (PAE), los cuales fueron impulsados por un nuevo grupo de acreedores que cobraba mayor presencia en la región (Ezcurra, 1997, pp. 18-19). 
La aplicación de los Programas de Ajuste Estructural, denominado también el Consenso de Washington, significó la estandarización del recetario neoliberal que tuvo como estrategia la consecución de diez puntos medulares: "recortes de los gastos en políticas sociales e inversiones, con el objetivo de 'equilibrar' el presupuesto estatal; prioridad en los gastos públicos del pago de los intereses de las deudas externa e interna; reforma fiscal; flexibilización del mercado financiero para la presencia de bancos internacionales y eliminación de las restricciones al flujo de capital especulativo internacional; equiparación de las monedas nacionales al dólar; eliminación de las restricciones a la inversión extranjera; programa de privatizaciones; desregulación de las actividades estratégicas (minería, transporte; prospección) y de las relaciones laborales (reformas); nueva ley de patentes, acorde con las exigencias internacionales" (Silva, 2006, pp. 6-7).

En el caso específico costarricense, se experimentó un recorte sostenido respecto al papel que había mantenido el Estado durante el período comprendido entre 1950-1980, que había logrado, entre otras cosas, impulsar una serie de obras de infraestructura y cobertura estatal que permitieron al país facilitar actividades dirigidas a la exportación y el mejoramiento de la calidad de vida de la población nacional (Hidalgo, 2007, p: 4), entre las que se posicionó la expansión educativa como uno de sus principios rectores. Un ejemplo de lo anterior es que en los años comprendidos entre 1956 y 1979 la inversión pública en materia educativa se duplicó llegando a ser el 6\% del Producto Interno Bruto para el último de los dos años mencionados anteriormente (Programa Estado de la Nación, 2005, p. 275).

En adelante, se impulsó en Costa Rica una agenda macroeconómica que fue compartida por el resto de los países de la región latinoamericana impulsada por tres ejes principales: a) “...constituir a las exportaciones en la fuente fundamental del crecimiento...", lo que lleva a políticas como el estímulo de "aperturas incondicionales" al capital transnacional y el sobreacento en la "competitividad"; b) reducir drásticamente el ámbito de acción del Estado y propiciar la privatización de toda suerte de actividades productivas y servicios...; y c) jerarquizar por encima de cualquier otro objetivo la preservación de los "equilibrios macroeconómicos" (sobre todo, en materia de presiones inflacionarias

3 Para respetarla identidad de cada estudiante creamos nombres ficticios. 
y de las cuentas fiscales y externas) (Ezcurra, 1997, p: 18-19). De esta forma, se pone freno a la tendencia creciente que había demostrado el Estado costarricense en materia educativa y la posibilidad e interés por el tema educativo pasa a un segundo plano, lo que llevó a la educación a un estancamiento que se manifestó en la inversión, el gasto público, la cobertura, la retención y la infraestructura educativa (Programa Estado de la Nación, 2005, p. 275).

Uno de los principales efectos de la disminución de la inversión estatal en materia educativa fue la contracción en la participación de los hijos de los sectores trabajadores en el sistema educativo formal. Mientras que en 1980, la proporción de escolares en relación con el número elegible para ese grupo era de $108 \%$, para el año 1987 había caído al $98 \%$. Al igual que en la primaria, las tasas en la secundaria descendieron del 48\% en 1980 al 41\% en 1987 (Grosh, 1990, p. 82).

Los recortes presupuestarios en el sector social, aunado a la pérdida de poder adquisitivo a nivel nacional, hicieron que los estratos medios retrocedieran de manera significativa en el escenario económico nacional y con ello necesidades básicas, como la educación, quedaron relegadas a un segundo plano para garantizar la satisfacción de necesidades tan sensibles como lo son el techo y la alimentación.

Aún cuando en Costa Rica, los estratos medios no se encuentran ligados estrictamente al aparato estatal, los que se encontraban asociados al Estado disminuyeron considerablemente al contraerse el papel de este último como empleador mayoritario. En este sentido, mientras que en 1987 el aparato burocrático captaba un 54,1\% de los estratos medios altos y un $28,9 \%$ de los estratos medios bajos, en 1995 estos porcentajes variaron de $45,9 \%$ y $21,2 \%$, respectivamente (Ruiz, 2001, p. 138).

Si bien es cierto, la década de los años 90 significó la recuperación de la inversión educativa, la posibilidad de las familias trabajadoras de mantener a sus hijos en el sistema educativo no sufrió variaciones significativas. Entre 1984 y el año 2000, la proporción de personas sin educación mantuvo un comportamiento relativo al 7\%, es decir, no sufrió modificaciones; sin embargo, la proporción de personas con nivel educativo de secundaria disminuyó considerablemente pasando de un $46 \%$ a un $25 \%$ respectivamente. En este sentido, se puede afirmar que el principal costo de la crisis de la década de los ochenta fue el fracaso de la cobertura y la permanencia de los jóvenes dentro del sistema educativo formal (Pérez, 2001, p. 2), principalmente aquellos provenientes 
de sectores trabajadores. Lo anterior se demuestra en el hecho de que mientras entre 1981 y 1986 el presupuesto dedicado a la educación se contrajo en un $6 \%$, los fondos destinados al $20 \%$ más rico crecieron en un $4 \%$ (Korten, 1997, p: 106), lo que las contradicciones económicas y sociales preexistentes, sino que propició el crecimiento de la brecha social y educativa que atraviesa este país.

Durante la época de ajuste, se dio el nacimiento de dos grupos antagónicos: el nacimiento de los nuevos pobres pero también el de los nuevos ricos. Según el investigador social Carlos Sojo, mientras que el $20 \%$ más rico del país se apropió del $50 \%$ del ingreso nacional, el $20 \%$ más pobre sólo se apropió del 4\% (Korten, 1997, p. 139-140). De esta forma, las transformaciones macroeconómicas que introdujeron los Programas de Ajuste Estructural se tradujo en una crisis estructural que tuvo impacto en el sistema educativo formal costarricense, la cual es cada vez menos capaz de motivar, interesar y formar, en tanto conocimientos, a las y los jóvenes.

Dado que en los últimos 30 años, la región latinoamericana en su conjunto se ha reorganizado en función de las necesidades estructurales de los países centrales, la mayor participación del sector privado en dinámica nacional-regional no es, sino, la coherente traducción de la rearticulación de las relaciones geopolíticas en las cuales, una vez más, los sectores de la burguesía local se articulan con los intereses de las necesidades de la burguesía imperialista. Según Arrieta (2007) "mientras el norte rico y no tan pobre del planeta se reorganiza en estas direcciones, el Sur pobre y muy pobre no hace y no hará otra cosa, en tanto perviva aún el capitalismo, que renovar y reordenar sus relaciones de dependencia económica respecto de los centros del Norte, rearticulando una vez más los vastos flujos de mercancías, dinero, riqueza, bienes, y ahora hasta trabajadores migrantes y explotados, que circulan sin cesar desde este Sur pobre hacia ese Norte rico y explotador". De esta forma, es posible comprender las dinámicas de privatización de los servicios básicos, como lo son la salud o la educación, como parte de una estrategia geopolítica de la cual Costa Rica es parte. 
Exclusión social como práctica pedagógica en la economía mundo capitalista: el caso del abandono del sistema educativo formal costarricense por jóvenes entre los 12 y los 18 años de edad (2000-2010)

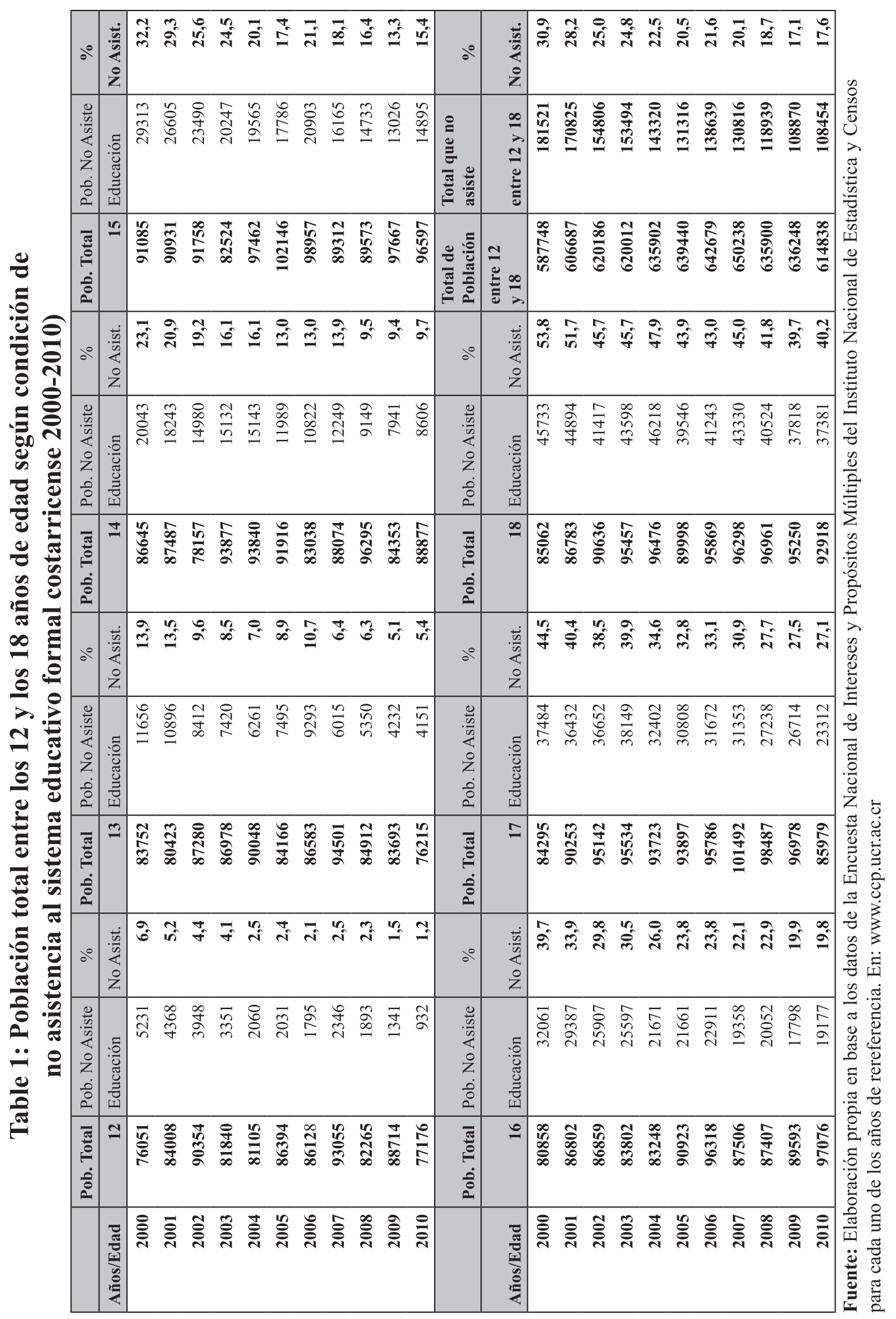


La tabla 1, arriba en este documento, permite identificar la dinámica que experimentó el fenómeno de la exclusión del sistema educativo en jóvenes entre los 12 y los 18 años de edad. Un primer elemento que se desprende del análisis permite evidenciar que entre los años 2000 y 2010 existe una tendencia sostenida a que las y los jóvenes se incorporen al sistema educativo formal. Sin embargo, lo anterior no se da como condición de una mayor dirección o interés del Estado costarricense por garantizar el acceso al conocimiento de su población, sino de cumplir con los requerimientos que ha impuesto el sector privado, principalmente aquel vinculado al desarrollo de tecnologías de punta del sector monopolista transnacionalizado, que ha puesto atención en los países semicoloniales o coloniales por la reducción de costos que implica producir en el Sur pobre y no en sus países de origen. Según Sandra Piszk, Ministra de Trabajo de la administración Chinchilla Miranda (2010-1014), "nuestros objetivos más importantes son: incrementar las capacidades laborales de la población con énfasis en grupos vulnerables que les permita obtener un trabajo, mantenerse y desarrollarse en sus opciones laborales con base a las exigencias del mercado..." (Ministerio de Trabajo y Seguridad Social, 2012). Lo anterior se da, principalmente, porque, al igual que en el pasado, los vínculos con el poder económico y político con que cuenta la burguesía local están articulados con el desarrollo de asociaciones corporativas transnacionalizadas entre el sector público, de los países pobres del sur, con los sectores monopolizados del norte imperialista. No es casualidad que en la actualidad la principal fuente de generación de empleo, 59\% del total, se dé en el sector privado (Trejos, 2008). Sin embargo, sólo un tercio de éste está representado por trabajo de calidad (Programa Estado de la Nación, 2008).

Según Antunes (2001), "el resultado más brutal de estas transformaciones es la expansión sin precedentes en la era moderna del desempleo estructural, que abarca a todo el mundo, a escala global. Se puede decir de manera sintética, que hay un proceso contradictorio que, por un lado reduce al proletariado industrial y fabril; por el otro, aumenta el subproletariado, el trabajo precario, o los asalariados del sector de servicios. Incorpora al sector femenino y excluye a las personas más jóvenes y más viejas. Por lo tanto, hay un proceso de mayor heterogenización, fragmentación y complejización de la clase trabajadora".

Un segundo elemento que vale la pena señalar, es la tendencia creciente hacia la exclusión educativa que experimentan las y los jóvenes en la medida en que ellas y ellos van alcanzado mayor edad. 
Independientemente del año de referencia, en la tabla se puede observar que en la medida que las y los jóvenes se van acercando a los 18 años de edad la posibilidad de tener acceso y permanecer en el sistema educativo formal tiende a disminuir. De esta forma, hay una distancia cuantitativa muy significativa al comparar los 932 casos $(1,2 \%)$ de jóvenes fuera del sistema educativo formal costarricense para aquellas personas que tenían 12 años durante el 2010, y los 37381 casos (40,2\%) de jóvenes fuera del sistema educativo formal costarricense para aquellas personas que tenían 18 años durante el mismo año. Esta diferencia cuantitativa, mayor a un $4000 \%$, evidencia la legitimidad pedagógica que ha impreso la explotación capitalista en el seno de la institución educativa. Es en ella, precisamente, que se normativiza, imprime, legitima, valida y reproduce la exclusión social como acción coherente de la explotación capitalista.

En la tabla anterior se puede identificar la tendencia creciente de las y los jóvenes, entre los 12 y los 18 años de edad, a abandonar el sistema educativo formal en la medida que ellas y ellos van adquiriendo mayor edad. Este elemento particular guarda relación con las necesidades materiales que atraviesa la clase trabajadora costarricense en la actualidad, principalmente al verse empleada en condiciones de mayor explotación, menor seguridad laboral y menor posibilidad de ejercer los derechos históricamente conquistados por la clase trabajadora en Costa Rica. Ante lo anterior, las y los jóvenes provenientes de la clase trabajadora tienden a incorporarse más tempranamente en la dinámica de reproducción del capital, principalmente porque la inversión social en Costa Rica está dirigida a los sectores más ricos de esta sociedad, lo cual se traduce en mejores oportunidades de acceso a bienes y servicios, mejores ingresos económicos, mejor participación y cobertura en el sistema educativo formal, entre otros (Programa Estado de la Nación, 2004, p. 98). Un ejemplo de lo anterior, son las diferencias cualitativas que privilegian a los sectores más ricos de la sociedad costarricense en vez de los más pobres. Según el Programa Estado de la Nación (2004), durante la década de 1990 la inversión social captada por el quintil más rico de la sociedad costarricense superó en un $64,1 \%$ la recibida por el quintil más pobre. Para el 2002, esta distancia había disminuido, sin embargo, el quintil más rico recibió un $48,8 \%$ más de inversión social que el quintil más pobre (Programa Estado de la Nación, 2004, p. 102). Para el año 2010, la diferencia cualitativa respecto de la posibilidad de 
tener acceso a mejores condiciones de vida estuvieron también dirigidos hacia los sectores más ricos del país privilegiándoles en su acceso y participación en el mundo del trabajo. Si bien, para el último de los años señalados, la tasa de desempleo abierto se redujo en términos generales, "los descensos más significativos se dieron en los quintiles de mayor ingreso. De esta forma, la relación entre el desempleo del primero y el del quinto quintil aumentó, de 7,9 veces en 2008 a 9,2 veces en 2010" (Programa Estado de la Nación, 2011).

Uno de los principales pilares de la dinámica anteriormente señalada reside en las tendencias del propio desarrollo capitalista. En la medida, que el desarrollo capitalista va mutando hacia nuevas prácticas, en tanto, actividades económicas (hoy marcadas por el desarrollo de tecnologías de punta), también va garantizando la reproducción de valorización del valor (explotación capitalista) ensanchando los propios circuitos de reproducción capitalista en aquellos espacios geográficos en los cuales dicha economía se dinamiza. Lo anterior permite establecer las condiciones ideales de reproducción de fuerza de trabajo a escala planetaria, las cuales estarán marcadas necesariamente por la contradicción. De esta forma, las y los jóvenes burgueses tendrán las condiciones objetivas y materiales para permanecer en el sistema educativo e incorporarse, posteriormente, al mundo del trabajo con ventajas comparativas muy superiores a la de las y los jóvenes de clase trabajadora. De esta forma, la propia dinámica educativa garantiza las condiciones básicas de reproducción social de la desigualdad, de exclusión y de explotación, lo que permitiría asegurar que en el salón de clase donde se legitima el orden capitalista imperante.

De lo que se trata, en última instancia, es de garantizar la existencia de volúmenes en proporción suficiente de fuerza de trabajo que garanticen la dinámica de reproducción del capital. Sin embargo, lo que habría que entender aquí, es que la dinámica de estratificación social permite a los sectores burgueses utilizar los mecanismos necesarios para garantizarse una posición privilegiada respecto a los medios de producción. De esta forma, la exclusión de jóvenes del sistema educativo costarricense responde a la dinámica de la economía-mundo capitalista, en tanto, que entre el 50 ó $60 \%$ de la generación mundial de empleo en la actualidad están dirigidos, principalmente, hacia la creación de puestos cuyos perfiles requieren personal de baja cualificación, ante 
lo cual la inversión social en materia educativa no es económicamente rentable (Hirtt, 2004, p. 9-10).

La dinámica de exclusión del sistema educativo que atraviesan decenas de miles de jóvenes en el contexto costarricense son el resultado de la articulación local con la economía planetaria, la cual tiende a precarizarse con mayor celeridad. Las condiciones de empleo y subempleo que se manifiestan a escala planetaria en la actualidad están ligadas con dinámicas estructurales que tienden a recudir "el proletariado fabril, industrial, manual, especialmente en los países del capitalismo avanzado, sea como consecuencia del cuadro recesivo, o por la automatización, la robótica y la microelectrónica" (Antunes, 2001, p. 56). De esta forma, existe una "tendencia extremadamente significativa, marcada por la subproletarización del trabajo, bajo las formas de trabajo precario, parcial, temporario, subcontratado, "tercerizado", vinculados a la "economía informal" (Antunes, 2001, p. 56).

Según el Estado de la Región (2008) "en el año 2006, el 30\% de los ocupados laboró jornadas parciales y el 33\% jornadas superiores a la normal. Durante el último quinquenio, uno de cada tres nuevos trabajadores se insertó en el mercado laboral con jornadas parciales y cuatro de cada diez en sobrejornadas. Esta situación podría estar relacionada con el incremento del autoempleo y la creciente inserción de las mujeres, lo que probablemente ha aumentado la presencia de la jornada parcial, mientras que un mayor empleo en empresas privadas de mayor tamaño ha intensificado el uso de la mano de obra. Este parece ser el caso de Costa Rica y El Salvador, donde cada vez más el sector empresarial opera jornadas por encima de la normal" (Programa Estado de la Nación, 2008, pp. 152-153).

Los elementos anteriores permiten identificar que la dinámica de exclusión educativa está ligada estructuralmente a la explotación capitalista y que ésta, en el mundo del trabajo, se articula con la generación de empleo precario, cuya remuneración, cumplimientos de derechos laborales y sindicales, cumplimiento de las normativas nacionales e internacionales son igualmente precarias y se desarrollan en ausencia del cumplimiento de los derechos individuales y colectivos.

Es precisamente en este escenario que las trabajadoras y los trabajadores, principalmente las y los más jóvenes, han asumido como propias las nociones pedagógicas que ha introducido el capitalismo en la dinámica educativa nacional: si se desea participar de la dinámica 
de explotación capitalista, habrá que asegurar cumplir con los requerimientos que el capitalismo establece para lograrlo. De esta forma, las y los jóvenes, principalmente aquellas y aquellos con menor capacidad económica que atienden la educación pública costarricense, cuentan con menos posibilidades de lograr insertarse en el actual contexto económico. Según el informe del Estado de la Nación (2003), "siguen siendo preocupantes las brechas entre la educación privada y la pública, que se reflejan en aspectos como infraestructura, repitencia y deserción. A manera de ejemplo, el porcentaje de repitencia en las escuelas públicas en 7.3 veces más alto que en las privadas y, en cuanto a deserción, en los colegios públicos los jóvenes desertan siete veces más que en los colegios privados" (Programa Estado de la Nación, 2003).

Según los distintos sectores corporativos que se hacen eco en los medios de comunicación de nuestro país, existe una necesidad imperiosa de articular, aún más, la educación pública con las necesidades y requerimientos del sector privado. Cordero (2012) señala que "Si el país quiere pasar del dicho al hecho y saltar a la economía del conocimiento, deberá ajustar rápido la red de centros de investigación y la formación del recursos humanos para que responda al actual modelo de desarrollo. Un modelo que busca atraer inversión extranjera directa y ligar la producción nacional a campos como las tecnologías digitales, el espacio y la biotecnología". De esta forma, tanto las y los jóvenes provenientes de los estratos altos como los que no, han comprendido que su fuerza de trabajo, en tanto mercancía que se tranza en la dinámica de mercado, adquiere mayor valor de cambio en la medida que el valor de uso sea requerido por el sector monopólico transnacionalizado que se ha afincado en Costa Rica. Así, las y los jóvenes, sus familias y la sociedad costarricense en general ha incorporado la exclusión social, la desigualdad y la contradicción como un mandato de la economía-mundo capitalista que debe ser atendida individualmente, por lo cual la reducción de las tasas de exclusión del sistema educativo han tendido a reducirse.

Lo anterior no significa, bajo ningún argumento, que quien participe de la dinámica educativa se ha garantizado la promesa de la "movilidad" o el "éxito". Todo lo contrario, la dinámica de la economía-mundo capitalista ha logrado trasladarle al individuo la responsabilidad colectiva del Estado. De esta forma, en el ámbito local costarricense, las y los jóvenes aceptan con resignación la exclusión educativa como una máxima que imprime el capitalismo en sus vidas. 
Para el grupo de jóvenes que se ha mantenido sin incorporarse a los procesos educativos, las condiciones de empleo, así como los conocimientos y saberes para aportar a la transformación local-regional, no sólo es limitada, sino que está condicionada, precisamente, por las dinámicas estructurales que han sido moldeadas por la propia economía-mundo capitalista. De tal forma, que tanto el sentido ideológico-histórico impuesto por la burguesía nacional, como la internalización de dicho discurso por parte los sectores de trabajadoras y trabajadores, ha permitido que la responsabilidad colectiva se individualice responsabilizando a las y los excluidos por las condiciones estructurales de su propia exclusión. De esta manera, se borra el sentido histórico-estructural de la exclusión al tiempo que se descalifica y se juzga a quien ha sido históricamente explotado.

Lo anterior ha sido revestido con el discurso positivista de la "selección social", que no es, sino, el discurso ideológico, asumido pedagógicamente en el contexto escolar, que garantiza la reproducción de las condiciones histórico-estructurales de la desigualdad, la contradicción y la exclusión social, las cuales tienen sus remanentes en la incorporación regional centroamericana a los circuitos de reproducción capitalista.

\section{Conclusiones provisionales}

Dado que las explicaciones científicas tienen un sentido provisional, que tendrían que ser sometidas a un ejercicio de validación o refutación futura para que sus conclusiones pudiesen ser sostenidas a través del tiempo, los elementos aquí planteados, en tanto conclusión, tienen un sentido temporal y espacialmente válidos. Sin embargo, no por eso, son menos significativos.

Durante el proceso analítico, se ha logrado constatar que la articulación del fenómeno educativo en Costa Rica tiene una importante vinculación con el desarrollo histórico de la economía-mundo capitalista, la cual respondió, sobre todo, a las necesidades e intereses de hacerse con el poder de las estructuras económicas e institucionales del Estado-nación costarricense por parte de un sector específico de esta sociedad que articuló sus relaciones económicas y políticas con el centro imperialista. De esta forma, la naciente burguesía costarricense del siglo XIX, operó a través del ejercicio de una violencia simbólica que 
impuso la noción ideológica liberal a través del control de la institución educativa y de la opinión pública.

La imposición imperialista, a través de la expansión de los circuitos de reproducción capitalistas, articuló una red de países semicoloniales y coloniales que le han garantizado, a los países centrales del Norte un papel privilegiado en la dinámica propia de la economía-mundo capitalista, que le ha permitido saquear y explotar a un amplio contingente de materias primas y fuerza de trabajo en el cual la dinámica educativa se ha articulado con el sentido de reproducir históricamente las condiciones de explotación capitalista.

La subdivisión internacional del trabajo, organizada en función de la explotación y saqueo de los países pobres por parte de los países ricos, es la máxima de la geopolítica del poder económico, en la cual la educación ha establecido un eje articulador a través de los distintos experimentos que la región latinoamericana ha atravesado. Sin embargo, en ningún momento se puso en entredicho las condiciones estructurales de la desigualdad, y éstas, más bien, han tendido a incrementarse.

La actual fase imperialista, denominada como "neoliberalismo", ha trasladado las responsabilidades estatales y colectivas al individuo, de tal forma que se validan y reproducen las condiciones histórico-estructurales del capitalismo, en tanto, que el desarrollo económico en la actualidad urge de conocimientos de mayor especialización. Lo anterior, le ha trasladado al individuo la noción cosificada de que la educación será quien brinde las condiciones cognitivas que le permita obtener un trabajo de calidad, cuando en realidad la praxis capitalista garantiza la reproducción capitalista a través del incremento de las tasas de plusvalía, por lo cual la mayoría de los trabajos de la región centroamericana y el país no brindan las condiciones mínimas de cumplimiento de derechos laborales. De esta forma, se podría concluir que el principal sentido pedagógico que ha impreso la economía-mundo capitalista, en su articulación con la dinámica educativa, es que el ser explotado es la responsabilidad de quien lo sufre en carne propia.

El mensaje para las y los 108454 jóvenes que representan el $17,6 \%$ del total de jóvenes entre los 12 y los 18 años de edad es abiertamente contradictorio. Aún cuando ellas y ellos ingresen al sistema educativo formal su futuro, en términos laborales, no estará garantizado, por lo cual si logran ser explotados en la dinámica de reproducción capitalista tendrán incluso que dar las gracias por ello. 
El proceso de construcción histórico de las instituciones sociales en Costa Rica deben ser entendidas como una tarea imperiosa para el funcionamiento de la reproducción capitalista, cuyo objetivo es la generación y extracción de plusvalía. En este sentido, la dinámica educativa costarricense debe ser entendida como uno de los principales agentes dinamizadores de la imposición imperialista en el ámbito local. De esta forma, quien pretenda enfrentar los retos de la exclusión educativa deberá enfrentar a su vez la necesidad de replantear el orden hegemónico que sostiene atada a la institución educativa.

\section{Referencias bibliográficas}

Aguirre, C. (2007). Immanuel Wallerstein y la perspectiva crítica del análisis de los sistemas-mundo. En Wallerstein, I (Ed.), La crisis estructural del capitalismo (pp.7-47). Colombia: Ediciones Desde Abajo.

Antunes, R. (2001). ¿Adiós al trabajo? Ensayo sobre las metamorfosis y la centralidad del mundo del trabajo. Brasil: Biblioteca Latinoamericana de Servicio Social. CORT6Z Editoria.

Cordero, M. (2012, junio 18-24). Ciencia reacciona lento en el país. Semanario El Financiero. $\mathrm{p} 4$.

Ezcurra, A. (1997, mayo-junio). Globalización, neoliberalismo y sociedad civil: algunos desafíos para los movimientos sociales y populares latinoamericanos. Revista Pasos, 71, 49-85.

Gandarilla, J. (2011). América Latina en la conformación de la economía-mundo capitalista. México: Centro de Investigaciones Interdisciplinarias en Ciencias y Humanidades. Universidad Nacional Autónoma de México.

Grosh, M. (1990). Social Spending in Latin America: The Story of the 1980s. Washington D.C. United States: The World Bank.

Fiszbein, A. (2001). Instituciones, provisión de servicios y exclusión social. Estudio de caso del sector educación en Buenos Aires. Revista de ciencias sociales Desarrollo Económico, 41 (162), 235-359.

Hessen, J. (1993). Teoría del conocimiento. México: Editores Unidos.

Hidalgo, C. \& Klimovsky, G. (1997). La inexplicable sociedad. Cuestiones de epistemología de las ciencias sociales. Argentina: AZ Editora.

Hirtt, N. (2004). Educación y mercado. Periódico Esto Pasa. p 4.

Korten, A. (1997). Ajuste estructural en Costa Rica, una medicina amarga. Costa Rica: Editorial Departamento Ecuménico de Investigaciones.

Lenin, V. (1966). El imperialismo, fase superior del capitalismo. Rusia: Editorial Progreso.

Marx, C. (2009). El capital. Libro I Capítulo VI (inédito). Resultados del proceso inmediato de producción. México: Siglo XXI Editores.

Menjívar, R. (1980). Acumulación originaria y desarrollo del capitalismo en El Salvador. Costa Rica: Editorial Universitaria Centroamericana. 
Pérez, H. (2001). Educación, capital humano y movilidad social en Costa Rica. Un primer análisis de los datos del censo de 2000. Costa Rica: Facultad Latinoamericana de Ciencias Sociales.

Programa Estado de la Nación en Desarrollo Humano Sostenible (2003). IX Informe Estado de la Región en desarrollo humano sostenible. Costa Rica: Programa Estado de la Nación.

Programa Estado de la nación en desarrollo humano sostenible. (2005). XI Informe Estado de la Nación. Costa Rica: Programa Estado de la Nación.

Programa Estado de la Nación (2008). Estado de la Región en desarrollo humano sostenible. Costa Rica: Programa Estado de la Nación.

Programa Estado de la Nación (2008). XVII Informe Estado de la Región en desarrollo humano sostenible. Costa Rica: Programa Estado de la Nación.

Quesada, R (2008). El pensamiento antiimperialista de Octavio Jiménez: Antología de Estampas publicadas en Repertorio Americano (1929-1938). Costa Rica: Editorial Universidad Estatal a Distancia.

Quijano, A. (1982). Clase obrera en América Latina. Costa Rica: Editorial Universitaria Centroamericana.

Ruiz, A. (2001). El destino de Costa Rica y la educación superior. El escenario histórico del país, la educación y el papel de la Universidad. Costa Rica: Editorial Universidad de Costa Rica.

Samper, M. (1988). Fuerzas sociopolíticas y procesos electorales en Costa Rica, 19211936. Revista de historia. Número especial, 1 (1), 157-222.

Silva, L. (2006). Ajustes neoliberales y luchas sociales: estrategias políticas en América Latina. Revista de teoría y política internacional Marxismo Vivo 1 (13), 5-13.

Torres Rivas, E. (1974, mayo-agosto). Poder nacional y sociedad dependiente: Las clases y el Estado en Centroamérica. Revista Estudios Sociales Centroamericanos, $8,27-63$.

Trejos. (2008). En: Programa Estado de la Nación. XV Informe Estado de la Región en desarrollo humano sostenible. Costa Rica: Programa Estado de la Nación.

\section{Documentos de Internet}

Centro Centroamericanos de Población, Universidad de Costa Rica. Encuestas de Intereses y Propósitos Múltiples del Instituto Nacional de Estadística y Censos (2000-2010). Recuperado de http//www.ccp.ucr.ac.cr

Ministerio de Trabajo y Seguridad Social (2012). Nuestros objetivos más importantes son incrementar las capacidades laborales de la población con énfasis en grupos vulnerables. Recuperado de http://www.facebook.com/note. php?note_id $=451978768178357$ 